\title{
CRITICAL CONSIDERATIONS ON GENDER AND TOURISM: A POSTSCRIPT
}

\author{
DONNA CHAMBERS* AND TIJANA RAKIĆ† \\ *Department of Tourism, Hospitality and Events, University of Sunderland, Sunderland, UK \\ †School of Sport and Service Management, University of Brighton, Eastbourne, UK
}

We begin this postscript by emphasizing that the impetus for this special issue on gender and tourism can be traced to two main concerns. The first is the seemingly intractable nature of gender (in)equality within the tourism sector despite some progress in the last few decades (albeit that this progress has been patchy and uneven within and across different geographical, cultural, and historical contexts). In a United Nations World Tourism Organization (UNWTO) Global Report on women in tourism, published in 2010 it was found that "women in tourism are still underpaid, under-utilized, undereducated and under-represented" (UNWTO, 2010, p. ii). Yet the UNWTO in the same report argued that tourism still represented one of the best means through which women could become empowered, particularly in developing countries. We recognized that over 7 years after this report was published there has been insufficient change in the circumstances of women in tourism in a general sense, although one can point to some case study exceptions. Even within tourism academia, recent studies have demonstrated the existence of gender inequality in leadership positions (see Munar et al, 2015; Pritchard \& Morgan, 2017), demonstrating that academia, despite its laudable rhetoric of developing criticality and reflexivity, is not itself necessarily a site for more equitable practices. Against this background, we felt that serious questions still remained about the complex and interlocking factors that result in the continued disempowerment of women in tourism and that have defied any sustainable transformation. The second impetus for this special issue was the relative dearth of investigations in tourism studies that sought to unpack the nature of gender relations through the application of different epistemological, methodological, and theoretical lens. We have suggested in our introduction to this special issue that, in tourism studies, rigorous academic work on gender only emerged in the 1990s (although several other disciplines and fields of study in the social sciences have been interrogating gender for several decades). Perhaps this reflects the relatively late theoretical development of tourism as a field of study. But it could also suggest that in tourism studies we have found it particularly difficult to throw off the shackles of the wider patriarchal structures in society that have traditionally elided the specific concerns of women and have ignored the importance of effective relationships between men and women for the proper functioning of the tourism system.

The five articles in this special issue have therefore provided very relevant discussions about gender 
and tourism from different critical theoretical perspectives and covering a range of geographical territories. In their article, Maliva, Bulkens, Peters, and van der Duim disrupt traditional essentialist concepts of the Third World woman as disempowered and lacking agency. Drawing on enactment theory, they used qualitative methods to explore the ways in which Zanzibari women in tourism leveraged entrepreneurial activities to challenge religious and cultural norms and practices. By enabling Zanzibari women to speak, to recount their own lived experiences, the authors have contributed to the furthering of critical scholarship that seeks to privilege the voices of black women from the Third World who have been historically silenced within tourism research. Similarly, the contribution by Foley, Grabowski, Small, and Wearing on the activities of women in the villages of the Kokoda track in Papua New Guinea provides further support for the way in which tourism can contribute to the empowerment of women in the Third World. Through their participation in a community-based ecotourism development project, they demonstrate how women of the Kokoda were able to use tourism to successfully negotiate traditional patriarchal power systems. Both of these articles have therefore provided counternarratives to hegemonic representations of the Third World woman in tourism as "victim."

The discussion in the article by Bakas, Costa, Breda, and Durão drew on feminist economics as a critical approach to interrogate the gender pay gap in the tourism industry in a peripheral region of Western Europe-Portugal. Through interviews with women employed in tourism, they found both horizontal and vertical segregation to exist in tourism employment. This confirmed the findings of previous studies on the gender pay gap in tourism (see, e.g., Skalpe, 2007; Thrane, 2008). However, what was interesting about this article was that their argument was grounded in feminist economic theory, a perspective that is scarcely articulated in tourism studies. Feminist economists have argued against the "gendered nature of Cartesian thought" (Nelson, 2009, p. 25), which stresses objectivity and rejects the social construction of reality. Nelson argued it is this Cartesian approach to the nature of the social world that has influenced the definition of economics as focusing on choice, a definition that views human decisions as "radically separated from physical and social constraints ... . [and] ignores non-physical sources of human satisfaction” (p. 32). Nelson goes further to argue that such a dichotomy (between the physical and the social) "merely reinforces the separation of humans from the world" and what feminist economics does is to consider "humans in relation to the world" (p. 32, emphasis in original). What the article by Bakas et al. has done is to demonstrate how one can apply feminist theorizing (in this case to economics) in order to understand gender (in)equality in tourism employment. In seeking to unpack the nature of women's employment in tourism from a feminist perspective, they listened to the voices of the women themselves in terms of their lived experiences of the tourism world.

Two articles focused on the gendered nature of arctic landscapes albeit from two different geographical contexts. Yudina, Grimwood, Berbary, and Mair directed our attention to British Columbia in Canada whereas Cassel and Pashkevich explored the Nenets Autonomous region in the Russian arctic. What both studies found was that representations of these arctic landscapes were patriarchal and reproduced dominant gender stereotypes. Yudina et al. went further to argue that dominant gender stereotypes were also inscribed onto the bodies of the nonhuman animals (specifically polar bears) that inhabit these arctic locales. Both articles have therefore contributed to furthering our understanding of the power of representation to (re)produce and (re)create northern landscapes as gendered with all the power relationships that this implies.

The common thread running through all five articles in this special issue is that they have all drawn on critical theoretical perspectives in their explorations of gender and tourism; these have included enactment theory (Maliva et al.), postcolonial feminism (Foley et al.), feminist economics (Bakas et al.), and critical discourse analysis (Yudina et al.). By so doing they have made important contributions to the critical canon of tourism research and scholarship. Indeed, Small, Harris, and Wilson (2017) in a bibliometric analysis of five top ranked tourism journals between 2005 and 2015 found that only a very small percentage of the articles published on gender examined this complex issue from a critical theoretical perspective. All five articles in 
this issue have also drawn on qualitative approaches to facilitate more in-depth understanding of gender and tourism that go beyond the superficial.

However, many avenues remain for the development of gender and tourism research and scholarship and we need to ask ourselves, as Morley (2005) has suggested, "What are the aspects of gender inequality that universally disturb and discomfort?” (p. 211). We discuss below some of the areas for further research that we see as imperative:

- We particularly encourage more theoretical and interdisciplinary applications. Specifically, we see the need for more interventions in the context of cultural relativism as it relates to "women's rights as human rights," an issue that we referred to in our introductory narrative. We also propose that more research be done on how globalization and neoliberal policies (political-economy approaches) have affected women in tourism, and also how continued sexual abuse and violence against women is relevant in a range of tourism employment contexts including academia.

- We encourage more research into gendered representations of humans, nonhumans, and landscapes within tourism. In this context, we see room for explorations of the "gendering of morality" (Dowler, Carubia, \& Szcygiel, 2005) within tourism landscapes and how an uncovering of oppressive practices might inform government tourism policies.

- We see the need to embrace increased polyvocality and intersectionality in gender and tourism narratives, particularly from those from marginalized cultures, races, ethnicities, locales, languages, and a host of other identifications. Such intersectional approaches would recognize the inadequacy of homogenizing perspectives that elide the importance of diversity and difference. We need to recognize in our research on gender and tourism that not all women are white, middle class, heterosexual, mothers, or nondisabled. Intersectional approaches to gender are not, as some would argue, expressions of a "kind of interminable negativity evident in the pile up of oppressions with its implicit hierarchization of suffering” (Friedman, 1998, p. 20). Instead, from such intersectional perspectives can emerge a "dialectical analysis whereby the multiplication of oppression creates its antithesis, a multiple richness and power centred in difference" (Friedman, 1998, p. 20, citing Audre Lorde).

- We see the need to embrace more critical perspectives, more innovative and creative methods. In this sense, we need to also avoid what Morley (1996) has termed the 'insensitive application of inappropriate research methods' (p. 131) that has led to female, black, and working-class people (and we would add lesbian, gay, bisexual, transsexual, and queer people) being researched only in relation to the dominant group and "socially positioned as 'other' " (p. 31).

- There is also more space for work on men and masculinities because as mentioned in our introduction, much of the work on gender and tourism focuses on women and is written by women. Indeed, this point was made by Swain (1995) more than 20 years ago and there have only been limited attempts thus far to address this gap in gender and tourism research.

Finally, we see gender and tourism research as central to a wider political project of transformation of ourselves as researchers, of our research participants, and of the very structures of our institutions and societies for the enhancement of the lives of all humans, nonhumans, and the planet that sustains us. But we must end with a caveat: while our project in compiling this special issue is an emancipatory one, we do not position ourselves in some kind of evangelical role that would discursively construct us as "saviors." Indeed, as Morley (1996) argued, "even to believe that we can access the 'truth' of women's experiences is reminiscent of an Enlightenment project” (p. 139). So, as tourism researchers we need to be highly self-reflexive about our own subjectivities and to remember that our research is as much about our own journeys of emancipation as it is about that of our research participants.

\section{References}

Dowler, L., Carubia, J., \& Szcygiel, B. (2005). Gender and landscape: Renegotiating the moral landscape. London, UK: Routledge.

Friedman, S. (1998). Mappings: Feminism and the cultural geographies of encounter. Princeton, NJ: Princeton University Press.

Morley, L. (1996). Interrogating patriarchy: The challenges of feminist research. In L. Morley \& V. Walsh (Eds.), 
Breaking boundaries: Women in higher education (pp. 128-143). Bristol, UK: Taylor and Francis.

Morley, L. (2005). Gender equity in Commonwealth higher education. Women's Studies International Forum, 28, 209-221.

Munar, A. M., Biran, A., Budeanu, A., Caton, K., Chambers, D., Dredge, D., . . . Ram, Y. (2015). The gender gap in the tourism academy: Statistics and indicators of gender equality. Copenhagen, Denmark: While Waiting for the Dawn.

Nelson, J. A. (2009). The study of choice or the study of provisioning? In M. A. Ferber \& J. A. Nelson (Eds.), Beyond economic man: Feminist theory and economics (pp. 23-36). Chicago, IL: Chicago University Press.

Pritchard, A., \& Morgan, N. (2017). Tourism's lost leaders: Analysing gender and performance. Annals of Tourism Research, 63, 34-47.
Skalpe, O. (2007). The CEO gender pay gap in the tourism industry: Evidence from Norway. Tourism Management, 28(3), 845-853.

Small, J., Harris, C., \& Wilson, E. (2017). Gender on the agenda? The position of gender in tourism's high ranking journals. Journal of Hospitality and Tourism Management, 31, 114-117.

Swain, M. B. (1995). Introduction: Gender in tourism. Annals of Tourism Research, 22(2), 247-266.

Thrane, C. (2008). Earnings differentiation in the tourism industry: Gender, human capital and socio-demographic effects. Tourism Management, 29(3), 514-524.

United Nations World Tourism Organization. (2010). Global report on women in tourism. Madrid, Spain: Author. 